to safeguard him and them. It would be interesting to know in what laboratory doctors are dehumanized. I am not aware that the laboratory experience of any save an extremely small number of physicians is of such extent that it would bear much more than mere mention.

I purposely refrain from speaking of one feature of. the Emmanuel movement which solicits careful investigation; that is the statements of Dr. Worcester, his disciples and fellow-practitioners regarding the frequency of functional nervous disease and the success that attends their treatment. If any one can believe that they cure 80 per cent. of cases of inebriety no word of mine will awaken him, for he is luxuriating in a glorious vision of the promised land, the millenium to come when this miserable world, freed from the fetters of alcohol, insanity, immorality, imbecility and illegitimacy, shall be no more.

But it seems incredulous that any opinion emanating from an individual who makes a statement so wholly devoid of fact as the one which I am about to quote should have the slightest weight with any one capable of reasoning. Bishop Fallows, who is the champion of the Emmanuel movement in Chicago, has recently written a book entitled "Health and Happiness," which contains the following paragraph:

"The functional disorders of the nervous system are quite modern. They appeared some time in the last century and were never known before in the history of the human race. They are so comon now that the physicians designated as neurologists could not take care of one-tenth of 1 per cent. of these cases.

Now I submit that if one were to characterize briefly the mental or moral status of an individual who made such a statement he would be reduced to the use of brief words and very few of them. Every one who has even an elementary knowledge of the history of the middle ages knows of the ravages of the so-called functional nervous diseases in that period. Tome on tome of literature and statistics attest it. In fact, I could successfully defend the thesis that functional nervous disease is no more common now that it was 300 years ago.

\section{PSYCHOTHERAPY OF THE EMMANUELITES}

As an example of the suggestion in psychotherapy, I may quote from a recent lecture of Dr. Worcester in New York, in which he told in glowing terms how insomnia and the alcoholic habit were overcome by suggestion. His suggestion for those who have insomnia was, "When you retire, think of the beautiful things of Nature. Imagine you are on the brink of a placid lake; then think of the soft moonlight as it falls on the peaceful water." Yes, indeed, if the baby suddenly cries while you are in the midst of such aliuring thoughts, or your wife insists that you go down and put the furnace in shape for the night, keep in mind that the placidity of the lake has not been disturbed in the meanwhile and that the moonlight is just as soft as before your sweet dreams were rudely disturbed!

Fellow practitioners, let us have zeal of God, but let us have it according to knowledge.

37 West Fifty-Fourth Street.

Education of the Unfit.-Charles G. Kerley, in the Archives of Pediatrics, states that over-education of the unfit brings forth tastes, habits and desires of which the individual should know notbing, and is the cause of more thieving, gambling and all-around dishonesty than is well appreciated. When position and wealth and reasonable competency do not follow by legitimate means, others are readily seized on.

\section{Original Articles}

\author{
THE PRESENT RELATIONS OF PSYCHO- \\ THERAPY \\ ROBERT T. EDES, M.D. \\ Bostox
}

The answer to the question whether the pathologist can ever draw a sharp line between organic disease and functional disturbance is yet.far off. Newer methods are constantly narrowing the list of maladies of which the organic substratum has been hitherto unknown.

Every expenditure of nervous energy, every mental action, every emotion, is undoubtedly accompanied by a subtle change in a larger or smaller group of neurones, some breaking down of the complicated vital molecules into simpler ones more closely akin to the inorganic, more accessible to the microscope and the test-tube. Fatigued tissues can be recognized under the microscope, and when the balance between fatigue and repair is broken for too long a time permanent degeneration is manifest. It is more in accordance with our knowledge of tissue metamorphosis and of toxic action to assume that the material change is the primary one. The rapid action of many poisons upholds this view, which may fairly be expected to cover those poisons of internal origin.

The assumption of a general control of structure and action by thought, without knowing what thought is or where it has its origin, a well-rounded theory of the complete dependence of health and disease on the mental attitude, is a convenient generalization and opens up a picturesque pathway along which one may stroll at leisure with many diversions until he is brought face to face with some hard pathologic facts.

The hotbed culture of hybrid new thought is a rapid and easy process admitting of a theoretic perfection entirely unattainable as yet by the slow growth of biologic science based on physics, chemistry and anatomy.

For our practical needs it is desirable to bring as much of the borderland as possible within the limits of the known and measurable and to ascertain where they come together.

It is not so very long since the doctrine of the dependence on the bodily health of correct mental action, of the emotions, even of theologic views, a comfortable digestion, a happy life (in this world at least), was the one popularly taught. It was summed up in various proverbs, such as "mens sana in corpore sano," and the pun "whether life is worth living depends on the liver," etc.

Even in the confusion of claims of the various theories and specialties, each for itself, this doctrine, far from growing obsolete, continues to cover an enlarging field in diagnosis, and as morphology is being supplemented by biochemistry, it more nearly covers the whole. And not only for therapeutics in the narrowest sense, but for preventive medicine, it is by far the most potent theory for good.

Now in the minds of hundreds of thousands, perhaps more correctly millions, this relation is reversed. That "strong will with which anything could be done," and which was considered one of the good gifts of Providence, is now within the reach of any one who will put himself for a time under the influence of a stronger one or even of a meaningless verbiage. 
The comfort and usefulness of decision and fortitude in bearing disease, as well as other misfortunes, is not to be underrated. The contribution to the happiness of many persons by instruction in firmness and serenity of mind given by so many sects of mental healing may be of great value. Whether the more recent instructions are more valuable and efficient than the old is another question.

But courage and patience are not new discoveries, nor are they the restoration of health. The invalid may do much and valuable work. In fact, a good deal of the best work in the world has been done by invalids; but it has been done in spite of disabilities, not by getting rid of them.

The normal control of the psychic centers over the functions of the rest of the body is only within a very limited extent a direct one. Strangely enough the connection is most easily interrupted where it is least roundabout, as in the paralyses and anesthesias. The very point at which the circuit seems most direct is that at which the psychic force meets its highest resistance, which may be raised or made absolute by organic disease. It is only when these paralyses and anesthesias are purely inorganic or functional, that is, when they depend not on the severance of organic connection between the psychic centers and the peripheral connections, but on the disarrangement of association centers, that the will or mind of the patient or physician can be made to influence them usefully. (This, of course, does not refer to conditions in which the training of a new set of muscles or even new centers can be made to take up the movements of others disabled.)

Nothing can be much more hopeless than an attempt to make the will control purely psychic manifestations of organic degeneration in "general paresis," for instance; and almost as strong an expression may be used of a great share of the melancholies and other forms of insanity with which as yet neither morphology nor chemistry have established a definite connection with tissue changes.

On the other hand, for instance, the beneficial effect of thyroid feeding on the mental condition in myxelema is very clear. No one doubts the effect of the nutrition on the emotions.

Mental, that is, cerebral, action is connected with physical, that is, sensation and muscular contraction, by a series of paths which have comparatively little direct relation with the so-called "vital organs." It is only when morbid activity of these organs reaches a certain intensity that it normally forces its way to the upper consciousness, that is, awakens the attention. But the attention may be oversensitized by morbid associations. Here is the crucial point in the diagnosis: Are such activities trivial or not? Can they be physically banished?

Voluntary control over the movements of organic life is not great. In a notorious but highly exceptional case many years ago a person kept up, day and night, a rate of respiration several times the normal and far beyond the limits of voluntary imitation without notable impairment of health in other ways and finally recovered by two applications of a saint's shin-bone. But one can not by an act of the will quicken the beats of the heart.

Psychical excitement, manifest or concealed, will accelerate the pulse considerably. A utilization of this fact has been made for getting a sort of involuntary confession from criminals.
The route of psychic influence on nutrition, on the metamorphosis of tissue, is almost entirely through the vasomotor system, the smooth muscles and the secretory nerves.

Blushing and paling, often dependent on entirely peripheral disturbances of cardiac and vasomotor nerves (for example, those caused by heat and by alcohol), may also be strictly physiologic results of psychic action, which in its turn may be normal or occasionally controlled by a "fixed idea," a "dread," or "obsession."

The movements of the iris are controlled by drugs, by the distribution of light, by organic disease, and also by emotions, which we assume to be the result of associations taking place in the cerebral cortex.

The muscular act of vomiting may be set in motion by direct irritation of the stomach, as in cancer, ulceration, gastritis and irritant emetics, by certain emetics acting on the medulla, by intracranial pressure, by irritants reaching no nearer to the stomach than the pharynx or even the mouth, by disgusting sights and smells (which is a form of psychic association); and again, in a form, not always easy of diagnosis, of wearing, dangerous, even fatal, neurotic vomiting, it may result purely from the "fixed idea." Here the psychic comes very close to the organic, for a constant complete emptying of the stomach, no matter whether under the influence of a cancer or an idea, is in effect the same.

A more pleasing demonstration of the influence of the mind on digestion is to be seen in the dyspeptic who enjoys and digests a "big dinner" but can not get along with the carefully limited scientific feeding. "Better is a dinner of herbs where love is than a stalled ox and hatred therewith."

But even if this universally acknowledged power of the mind over certain bodily functions, which seems to be considered by some a recent discovery and is by many sects claimed as their peculiar property, be much less than many theories would make it; if we admit its strict limitations as a cure (not merely as a mitigation and relief), we find it utilized every day by every sect, consciously, subconsciously, unconsciously or unwittingly. Can any self-critical physician of experience for a moment suppose, in the face of the constant and rapid changes in therapeutic theory, that the recoveries in all his cases are attributable to the exact scientific adaptation of the drugs he has administered? If his patients recover to-day simply because he has employed the most modern and scientific methods, why are his earlier patients still alive? Why do those of his neighbor who follows another treatment recover also?

Every such candid physician treasures in his memory, if not in his case-book, recoveries which he did not expect and could not explain; others which he knew had nothing to do with the drug or the dietetic treatment instituted; others still in which he more than suspected that the batteries and the vibrators had only a "moral" effect; with a small residuum in which he could not help recognizing the predominance of his own personal influence and teachings.

He is not so likely to plume himself or the latter as on his appendectomies, for instance (or was not until he learned that his successful mental devices had also received a name just this because he supposes that the one testifies to real professional skill while the other, if heard of at all, is apt to be attributed to nothing in particular or merely good luck? The fisherman much prefers talking about the trout which jumped at his carefully selected fly to 
exhibiting the pout or eel which would gobble anybody's ignoble worm.

Is it possible to reduce the accumulated knowledge of the physician and the charlatan to a system? Like too much else of the experience of the busy man, the data of the practitioner are all too briefly recorded. If such episodes live in his memory they are likely to come to light with picturesque and dramatic distortions of years, chiefly as the basis of humorous stories at club suppers. The charlatan may be an enthusiastic, perhaps a learned one. He is more often a shrewd ignoramus or even a liar pure and simple. In the latter case he is no more likely than other manufacturers to give away his trade secrets. In the former case he is probably unable to do so in any language understandable by the common people. But with caution and patience he can be utilized.

Rough statistics, such as those collected by $\mathrm{H}$. $\mathrm{H}$. Goddard, based on interviews with patients and healers whom he thought to be honest, although uninstructed, reveal no astonishing proportion of recoveries; and the boasts of so-called religious leaders, and the recorded cures of these thaumaturgists (they are not in danger of being hidden) confirm these conclusions. The former set corresponds sufficiently well with the reports of scientific hypnotists; the latter can be matched in the recollection of many a practitioner who never suspected that he was stepping outside the plain practice of medicine into higher regions of psychotherapy.

The questions which arise in regard to modern practical schemes of mental healing are partly of principles, partly of methods and partly of persons; the most important, the fundamental one, that of the diagnosis of the. known, acknowledged, organic, from the functional, inorganic or psychic, between the structural lesions and the maladjustments, should be settled before mental healing is invoked. ${ }^{1}$

Is there underlying all the forms of cure, whether of the psychotherapist, the enthusiast or the utter charlatan, any common principle or condition which is an essential to recovery?

We must make the unpleasant, by no means flattering admission, that what goes to explain Lourdes or Ste. Anne de Beaupré must have its value in Paris or Nancy or Boston. Holy (even if dirty) water may be -in psychic analysis-the equivalent of bitter tinctures or animal extracts, or sugar plums.

Patients who like to narrate their cures like also to enhance the effect by stating that they "did not believe in it at all, but were persuaded by friends," and so on; but it is certain that faith, formally acknowledged, or unconsciously present, is a factor in all and the only factor in some recoveries. One of the curious contrasts in individuality is to be found in the effect of simple reiterated assertions, in one class of mind awakening only repulsion, in another intensifying and developing a nascent wish into a belief, or in a few even perhaps originating belief from chaos. No one knows this better and utilizes it to more advantage than the commercial and especially the medical advertiser.

The "otherwise minded," the man who really delights in opposition, is probably more highly endowed intellectually than his credulous brother. He is likely

1. Warning has been given by some of the early supporters of the religiotherapeutic movement, against the danger from it falling into too enthusiastic, but ignorant hands. The danger is undoubtedly a real one, but it is no more imminent, and possibly less serious, than may be found in the case of any other method (really useful or not) which appears in the guise of novelty. The an essential part of the system, the skilled careful diagnosis. also to be much more uncomfortable to himself and to his neighbors, much less profitable to the charlatan, and if his crankiness is brought to bear on his own health rather than on the conduct of the world in general he is a terror to his physician. Mary's little lamb followed her to school one day and undoubtedly remained as stupid as other sheep, but if she had been trying to make a pig a learned one she would have grasped the animal's tail and pulled as firmly in the opposite direction as possible.

When it is considered how many different disorders there are existing supposed to be amenable to mental treatment, and the infinite combinations wrought among them by individual peculiarities, heredity, education and environment, it seems that here more than in any other department of medicine each patient must be a case by himself. As to the development of this necessary faith it may in some be of that nature which attaches itself quickly to the nearest object. In many its development is capricious and dependent on some accident, some pleasing, apparently novel, aspect of a familiar idea. Comparatively few base their faith on a rational judgment.

Among all these is it possible to frame rules applicable by every one in procuring that confidence essential to success? It is the subconscious emotion, wish, longing, trust, confidence, rather than a logical conviction, which supports the forces working toward cure. Often the more completely unconscious it is the better, for it is less likely to be disturbed by intellectual doubt.

"The man convinced against his will is of the same opinion still."

The scoffings of the skeptic can be directed with less effect against a belief which rests on hidden foundations than against one which stands in full view with its weakness exposed. Faith in the occult and mysterious is in many persons easier to attain than confidence in a teacher, no matter how wise.

If from the effect of some unusual excitement on a predisposed constitution the subliminal consciousness becomes completely separated and assumes the control which should belong to the conscious reason, the conditions are ready for the rare miracle-cures which bulk larger in literature than in real life.

A successful scientific system of psychotherapy is as difficult to impart by formal instruction as is business shrewdness, social tact or political magnetism. Indeed, the latter simile carries suggestions which might lead us too far from the field of medicine. It would be as difficult to lead a student, sincere, well instructed, a little too sensitive as to his dignity, a little too fastidious, too careful of his scientific reputation, but without tact and common sense, to overcome these difficulties, to become a successful mind healer, as it would be to make a conscientious student of political economy into a successful "boss." It is largely a work of art, not a science; perhaps a work of Nature rather than either.

If we wish to fix more precisely the avenues of approach to the therapeutics of the lower consciousness, where it is now conceded that many psychoses principally have their stronghold, we might make a list somewhat like the following:

A. Assertion, positive and reiterated.

B. Instruction, persuasion and exhortation. Encouragement.

C. Free confession, including the "cathartic" or an" alytical method of Freud. 
D. Deception. Placebos. Drugs in which both the patient and physician have a kind of half-belief.

E. Suggestion, hypnotic or waking. The word is often given a much wider application than was at first intended.

Reason, sympathy, sarcasm, concerted action, interesting occupations, are among the methods to be carried out through these paths. That any one of them is to be looked on as the only avenue in all cases is absurd. They are to be applied with the most careful adaptation, not solely to the name of the disorder existing, but with just as careful diagnosis of peculiarities of the individual case.

One might suppose a practitioner trained in the oldfashioned form of compounding a prescription to put his directions somewhat in the following shape, either in his own mind or on paper, if to be placed in the hands of an assistant:

The essential active elements: Reason. Sympathy. Occupation? Shock?

The adjuvants: Rest, feeding, seclusion, exercise, passive or active, massage. Occupation?

The corrigents: Sarcasm. Judicious neglect.

Flavoring: The favorite theories of the patient, social, moral, theologic.

Vehicle: Faith. Authority of the church. Love of the marvellous. Attraction of the erowd. Enchantment of distance.

Misce secundum Artem. With TACT.

Such a prescription is not to be had in the tabloid form.

Some of these ingredients call for important practical remarks. Encouragement can hardly be used to excess, except in the mixed cases in which too absolute confidence in recovery might lead to neglect of essential hygienic or medicinal measures. Few circumstances are more encouraging than a steady gain in weight. Feeding is an adjuvant.

It is surely better to give a proper dose of quinin than to tell a patient he will not have a chill the next morning, although there have been cases in which the patient recovered after swallowing the prescription instead of the medicine.

The fixed idea of chronic obstruction of the bowels is quite as effectually abolished by a dose of calomel or castor oil as by the most elevating exhortations. And yet there have been cases in which

But the dosage of sympathy is that which requires the most careful adjustment. Too many patients, the chronic invalids, the neurasthenics perhaps incorrectly diagnosticated, have already had from their friends, the mother, the sister, the clergyman, or the doctor, too much of that enslaving narcotic. It may develop the trivial injury into a traumatic neurosis. It may prolong the indolence or aboulia due to a temporary cause, the neurasthenia which a moderate rest will restore, into a useless and joyless lifetime; and yet it is very hard to withhold it. Absolutely to omit it may be cruelty and disaster. The patient already accustomed to the overdose who comes into the hands of the neurologist should not have it reduced so abruptly as to cause shock or revolt, but later it may be taken away with a firm hand.

It is evident that sarcasm and neglect are to be introduced into the prescription with the utmost caution, and, at that, only in the rarest cases after a careful diagnosis.

As to the "flavoring," it is that which in psychotherapy makes a great part of the difference between the sects. As in many other prescriptions, it is by the flavor alone that the patient thinks he knows what he is taking.

It is in favor of the present use of the word "psychotherapy" that as yet it carries with it no suggestion of a special theory, and it is to be hoped that its popular use will not warp and twist it into the trademark of an exclusive system. The normal and proper influence of the physician's instruction, the clergyman's kindly rebuke or words of cheer, must not be allowed to degenerate into a superstitious reverence.

Among these subjects there are two likely, from their comparative novelty and their distance from the commonplace methods, to awaken more discussion and difference of opinion than others. These are hypnotism and Freud's analytic method.

The power of hypnotism for evil and the range of its applicability for therapeutic purposes have undoubtedly both been exaggerated, certainly as regards ordinary everyday use. Whether its habitual use tends to weaken the normal will, whether under special circumstances it may be used for criminal purposes (explicitly denied by its advocates), and whether it may in rare cases get a control which other less sensational methods fail to secure, I do not undertake to say. The power of persuasion, with or without hypnotism, which one person may obtain over another either for evil deeds or virtuous determination, varies immensely. In alcoholism, for instance, in which special claims have been made, it may be reasonable, professional, or friendly inducements, or personal determination, which lead to the abandonment of the pernicious habit; and, on the other hand, it is only too well known that everything, reasonable or occult, punishment, deceptive medication, family distress, as well as hypnotism, utterly fail of any permanent result in a large proportion of cases.

The induction of sleep in cases of insomnia is well known to be a frequent desirable result of monotonous sounds and sights, that is, the cessation of all external stimuli and disturbing thoughts, a sort of hypnotic power not reckoned as a merit in the clergy.

The importance of hypnotism in the psychoses, with the exception of hysteria, in which it is little but a change of form, and some of the lesser ones, in which it is unnecessary, might be thought from the closeness of the relation between the remedy and the disease, to be at its maximum. By this time, however, there must have arisen from the experience of many candid or even enthusiastic men a most conclusive consensus of opinion that it has done nothing to displace in practice the nonhypnotic suggestion (to use an overweighted phrase), or in other words, the persuasion, instruction, re-education and suitable employment which are to-day among the most important resources of the enlightened alienist.

There are reasons why it is desirable to avoid hypnotism in ordinary use. The possible abuse for criminal purposes, the impairment of the patient's will, and the liability to induce too great dependence of the patient on the mere personality of the physician are not objections of great weight. As much may be alleged against powerful drugs, as, for instance, alcohol and opium.

Since nearly all other methods of reaching the mind of the patient depend on a confidence in the knowledge and professional skill of the physician, it is of great importance that he should not jeopardize his influence by a failure to hypnotize, and many high authorities agree that it is only a certain proportion of persons who are hypnotizable. An unsuccessful experiment will 
materially impair the effect of the next attempt at rational persuasion.

Freud's method does not demand the induction of hypnotism, but an attitude of confidential trust evoked by long continued and careful questioning as to the earliest recollections which have given rise, through long trains of association, forcibly repressed or fallen below the threshold of present consciousness, to morbid psychic conditions largely of fear and depression.

The method has probabilities in its favor, but if it be possible in any given case to develop and strengthen what has been morbid suppression with its residue of doubt and fear into a complete rupture of associations, it would seem that such a short cut is preferable to the tedious questioning, which is almost certain to implant and vivify ideas of the very kind which it is desirable to get rid of. Some other plans of developing more speedily this desirable attitude of trust have been considered dependent on slighter grades of hypnotism, so-called hypnoidal conditions.

It is not necessary, if one intends to utilize the methods of Freud, to accept the extreme views of this acute psychic analyst, or to admit that every 'phobia has a sexual foundation. Fiven if it be true that this potent factor in the emotional life does not always, for very obvious reasons, receive the consideration it deserves, it is surely not the only one. Other motives, indeed, other motives which many a person prefers to ignore, may have as powerful an influence in the emotional development. It is necessary to accumulate a wider experience under different social conditions and with a greater variety of personalities before we accept so nearly an absolute connection between a single class of emotions and so narrow a clinical group.

By whom should the treatment be carried out? Obviously by the physician who makes the diagnosis, who should know better than any one else what is best adapted to the case, or else under his immediate direction, if he have the requisite characteristics, the good sense and the tact, which are of far more consequence than any details of method; if to an assured diagnosis he adds the firmness to carry out what he sees to be needed.

But it is true that he may be an excellent therapeutist and yet be lacking in some of the qualities desirable in the care of functional cases in general, as well as in the case before him.

Circumstances may be such that he can not undertake it. The method of Freud, for instance, demands a vast amount, not only of time but of patience, and although there are others which may lead to the same result more promptly, there are few of any kind which can be carried- out by the physician in the dispensary or the general hospital. It is not every man who can listen sympathetically to a daily rehearsal of imaginary, se' $\mathrm{f}-$ developed woes, or the maudlin details of a self-accuser.

It may be further noted that ignorance may have its advantages as well as its dangers. The complete diagnosis by exclusion is not always possible to every man in every direction; and between the same man acting as diagnostician and as therapeutist there can be no real intellectual gap. A nervous patient may be a shrewd observer. He may detect or suspect from the words or the manner of his healer that the diagnosis is incomplete and that the positive assurances are not quite sincere. There are few errors more mortifying, if not worse than mortifying, than overlooking an organic cause for symptoms which the patient must be assured are purely nervous. The scientist may be obliged to hedge a little for his own sake. But between the physician and his assistant, medical or otherwise, no matter how well instructed and loyal, there may be left a gap wide enough for doubts to shrink into the background and leave to the therapeutist the full advantage of absolute confidence in which the timorous patient can detect no weakness.

A very recent movement for combining the work of the physician and the clergyman, the diagnostician and the lay therapeutist, offers this among some other advantages. The bright light of enthusiasm, the uplifting of religious faith, the feeling of sympathetic companionship, perhaps a little of the "crowd madness," transform the scientific opinion into a moving force. Words of cheer, advice, appropriate music-one of the most powerful of emotional stimulants - may be addressed to dozens as well as to units and each may rightfully find his individual needs as carefully ministered to as if he had received a few hasty words and a scrap of paper from the hospital out-patient doctor, who can by no possibility give adequate thoughtful attention to each of his "nervous" clients.

It has been said, even by physicians, that an antagonism to psychotherapy exists among their brethren. It can hardly be true as regards the principle itself, but only against the extravagant claims based on a new nomenclature, against its misapplication, and especially the disgust with a multitnde of quackish practices whose genetic relationship can not be denied, but with which all fellowship should be shunned.

The specialist who sees nervous disorders which, as he knows, depend on organic changes in the nervous structure, not naturally reprobates as absurd and often cruel the effort to make a patient believe that a proper frame of mind is alone sufficient to get rid of the tumor. the inflammation, the toxin, the degeneration. But he can only be thankful if the patient can be taught to use another set of muscles to accomplish lost movements, to bring his will to bear on what is normally done automatically, or at least to bear unavoidable defects and suffering as well as possible. But he ought not to be allowed to cherish ideas which he can be shown are morbid or baseless or to suffer incapacities which can be removed.

An objection to this alliance has been heard from the other side to the effect that the church is deserting its proper work in administering to the bodily as well as the spiritual wants of its disciples.

As to what the proper function of the church as an organization may be, it does not become me to express an opinion, but considering the example and teaching of its head and the zeal with which these have been followed by so many of his disciples with no disastrous results for nearly 2,000 years, the outlook does not seem to an outsider alarming.

Maternal Impressions.-C. H. Melland, in the British Journal of Children's Diseases, states that the belief that the fetus may be influenced by impressions received by the mother during pregnaney is as old as history and, like other superstitious ideas which are the residue of deeply ingrained mental conditions dating back into the age of barbarism, it is displaced only with difficulty. Even in the present day, the possibilities of coincidence cre greatly underrated, mainly because those cases are placed on record in which the cause and effect seem satisfactorily established, while the far more numerous instances in which coincidence fails to produce any startling effects are silently passed over. 